\title{
Optimization for Permeability and Electrical Resistance of Porous Alumina-Based Ceramics
}

\author{
Jae Kim****, Jang-Hoon Ha*, Jongman Lee*, and In-Hyuck Song ${ }^{* * * *, \dagger}$ \\ *Powder and Ceramics Division, Korea Institute of Materials Science, Changwon 51508, Korea \\ **Korea University of Science \& Technology (UST), Daejeon 34113, Korea
}

(Received June 9, 2016; Revised August 1, 2016; Accepted August 2, 2016)

\begin{abstract}
Recently, porous alumina-based ceramics have been extensively applied in the semi-conductor and display industries, because of their high mechanical strength, high chemical resistance, and high thermal resistance. However, the high electrical resistance of alumina-based ceramics has a negative effect in many applications due to the generation of static electricity. The low electrical resistance and high air permeability are key aspects in using porous alumina-based ceramics as vacuum chucks in the semi-conductor industry. In this study, we tailored the pore structure of porous alumina-based ceramics by adjusting the mixing ratio of the starting alumina, which has different particle sizes. And the electrical resistance was controlled by using chemical additives. The characteristics of the specimens were studied using scanning electron microscopy, mercury porosimetry, capillary flow porosimetry, a universal testing machine, X-ray diffraction, and a high-resistance meter.
\end{abstract}

Key words : Alumina, Porous material, Air permeability, Electrical resistance

\section{Introduction}

$\mathrm{P}$ orous ceramics are of technological interest because of their potential use in applications. The air permeability, mechanical and thermal properties of this porous material can be controlled according to the changes of porosity and pore size. Porous ceramics have low density and large specific surface area so these are used in various fields due to the pore characteristics that dense materials haven't. ${ }^{1-5)}$ Among porous ceramics, porous alumina is sintered under an air atmosphere so it is less expensive and easy to obtain its raw material. Porous alumina also has high mechanical, physical, chemical and thermal stability and excellent corrosion resistance and electrical insulating properties, therefore porous alumina can be used widely in the industry. Because of such advantages, the demand for porous alumina is increasing in the display field as well as the semiconductor field as the subsidiary parts for semi-conductor manufacturing device. However, due to a high volume resistance of approximately $1 \times 10^{15} \Omega \mathrm{cm}$ of alumina, it is being used limitedly in handling rig, arms, pincette and heater for transferring wafer, vacuum tube parts and spacer for magnetic disc and semi-conductor vacuum chuck that are parts requiring the prevention of static electricity. Among these devices, a vacuum chuck for FPD (flat panel display) is a precision chuck which maintains the glass substrate or

${ }^{\dagger}$ Corresponding author : In-Hyuck Song

E-mail : sih1654@kims.re.kr

Tel : +82-55-280-3534 Fax : +82-55-280-3392 semi-conductor wafer.

However, if alumina is used as a vacuum chuck for FPD, a electric charge will be polarized inside the metal layer of thin film due to its high electrical resistance, resulting in a spark discharge and damaging the substrate. ${ }^{6}$ ) Therefore, a study on the control of electrical properties of alumina is urgently required in order to solve such electrostatic polarization. To solve such problem metallic oxides are added to alumina and such methods include the method to add both $\mathrm{MnO}_{2}$ and $\mathrm{TiO}_{2}$ to form $\mathrm{MnTiO}_{3}$ or add $\mathrm{MnO}_{2}$ to alumina, forming the second phase with low electrical resistance such as $\mathrm{MnAl}_{2} \mathrm{O}_{4}$ and the method to add $\mathrm{TiO}_{2}$ to form excess electron, and it is possible to lower the electrical resistance of alumina through such methods.

Also, excellent air permeability to apply the suction force and high strength to prevent damage from the suction process are required because a vacuum chuck is a device which adsorbs and transfers a substrate using the vacuum suction force. However, porous materials have a low strength generally due to high porosity, so there is a difficulty in using porous materials as a vacuum chuck. To solve this problem, there are several methods to improve the strength of porous alumina. The method to add $\mathrm{ZrO}_{2}$ which is a reinforcing material, the method to increase sintering time and sintering temperature and the method to mix powders in two different sizes are available. Among these methods, the method to mix powders researched by Furnas ${ }^{7}$ can fill pores between large powders with very fine powders so that high green density can be obtained. Also, the method to mix powders was presented in order to improve low mechanical properties and increase the density of the porous material. ${ }^{8-9)}$ 
However, if the density of porous material increases, its structure will become more dense due to high density regardless of increased strength so that the permeability will be lowered on the contrary. Therefore, it may be unsuitable to use as a vacuum chuck requiring a high permeability.

In order to solve such problem, it was intended to control the pore structure by generating a large open pore between large powders using relatively large powder mixture in this study, and relative large powders in two different sizes were mixed to obtain a relatively higher density than porous materials produced using powders in the same size and improve the strength. Also, $\mathrm{MnO}_{2}$ and $\mathrm{TiO}_{2}$ were added to control the electrical properties of porous alumina. And changes in the density, mechanical properties and pore structure according to the mixing ratio between powders in two different sizes were examined.

\section{Experimental Procedure}

The commercial alumina powders in three different sizes were used for the starting raw materials in this experiment, and (S) for small-sized powder, (M) for medium-sized powders and (L) for large-sized powder were named respectively for convenience as shown in Table 1. \#600 Mesh $(\sim 8.93 \mu \mathrm{m}$, 99.51\% white aluminum oxide, Kramer Industries, USA) for large-sized alumina powder, \#280 Mesh ( 33.43 $\mu \mathrm{m}, 99.51 \%$ white aluminum oxide, Kramer Industries, USA) for mediumsized alumina powders and \#180 Mesh ( 81.24 $\mu \mathrm{m}, 99.35 \%$ white aluminum oxide, Kramer Industries, USA) for large- sized alumina powders were used respectively. The same amount of metallic oxides was added to all specimens in order to control the electrical properties of alumina; $2 \mathrm{wt} \%$ of $\mathrm{TiO}_{2}$ (99.5\% Sigma-Aldrich, USA) and $4 \mathrm{wt} \%$ of $\mathrm{MnO}_{2}$ (99\% Sigma-Aldrich, USA) were used. The porous material was made only using alumina powders in same size for each specimen. Also, porous material using the mixed powder was made by adding large-sized powders to medium-sized powders at the weight-ratio of $0,30,50,60,70$ and 100 as shown in Table 2. Dry ball milling was carried out for $24 \mathrm{~h}$. PEG (polyethylene glycol, Sigma-Aldrich, USA) was sprayed and mixed as a plasticizer, and then it was diepressed at a pressure of $25 \mathrm{MPa}$ using the disk-type $36 \mathrm{~mm}$ mold. The pressed samples was heated at $600^{\circ} \mathrm{C}$ to burn out the binder and it was sintered at the maximum temperature of $1600^{\circ} \mathrm{C}$ with heating rate of $5^{\circ} \mathrm{C} / \mathrm{min}$ for $1 \mathrm{~h}$ in an air atmosphere to produce porous material.

In order to check the density variation according to the mixing ratio between powders in two sizes, the weight and volume of specimens produced according to each mixing ratio were measured and the relative density in comparison to the theoretical density was calculated. At this time, the theoretical density was calculated from the composition of raw material powders using the rule of mixture. Also, in order to check the pore size of porous material, it was measured using the mercury porosimeter (AutoPore IV 9500, USA) according to the mercury immersion method. The air permeability was measured using the Capillary Flow Porometer (CFP-1200-AEL, Porous Materials Inc., USA). The

Table 1. Chemical Compositions and Particle Sizes of Starting Alumina Powders Provided by Supplier

\begin{tabular}{ccccc}
\hline Alumina powder & & $\begin{array}{c}\text { White aluminum oxide grit } \\
\text { \#600 Mesh }\end{array}$ & $\begin{array}{c}\text { White aluminum oxide grit } \\
\text { \#280 Mesh }\end{array}$ & $\begin{array}{c}\text { White aluminum oxide grit } \\
\text { \#180 Mesh }\end{array}$ \\
\hline Designation & & $\mathrm{S}$ & $\mathrm{M}$ & $\mathrm{L}$ \\
\hline & $\mathrm{Al}_{2} \mathrm{O}_{3}$ & 99.51 & 99.51 & 99.35 \\
& $\mathrm{TiO}_{2}$ & 0.02 & 0.02 & 0.01 \\
& $\mathrm{SiO}_{2}$ & 0.00 & 0.00 & 0.05 \\
Chemical composition & $\mathrm{Fe}_{2} \mathrm{O}_{3}$ & 0.06 & 0.06 & 0.07 \\
(wt\%) & $\mathrm{CaO}$ & 0.04 & 0.04 & 0.06 \\
& $\mathrm{MgO}$ & 0.03 & 0.03 & 0.03 \\
& $\mathrm{Na}_{2} \mathrm{O}$ & 0.31 & 0.31 & 0.41 \\
& $\mathrm{~K}_{2} \mathrm{O}$ & 0.03 & 0.03 & 0.02 \\
\hline Particle size $(\mu \mathrm{m}) \mathrm{d}_{(0.5)}$ & 8.93 & 33.43 & 81.24 \\
\hline
\end{tabular}

Table 2. Powder Mixture Ratio and Chemical Composition of Porous Alumina-Based Ceramics

\begin{tabular}{|c|c|c|c|c|c|c|}
\hline \multirow[t]{2}{*}{ Designation } & \multicolumn{2}{|c|}{$\begin{array}{l}\text { Medium size - Large size } \\
\left(\text { Weight ratio of } \mathrm{Al}_{2} \mathrm{O}_{3} \text { ) }\right.\end{array}$} & \multicolumn{4}{|c|}{$\begin{array}{c}\text { Chemical composition } \\
\text { (wt\%) }\end{array}$} \\
\hline & $\mathrm{M}$ & $\mathrm{L}$ & $\mathrm{M}-\mathrm{Al}_{2} \mathrm{O}_{3}$ & $\mathrm{~L}-\mathrm{Al}_{2} \mathrm{O}_{3}$ & $\mathrm{TiO}_{2}$ & $\mathrm{MnO}_{2}$ \\
\hline M100-L0 & 100 & 0 & 94.0 & 0.0 & 2.0 & 4.0 \\
\hline M70-L30 & 70 & 30 & 65.8 & 28.2 & 2.0 & 4.0 \\
\hline M50-L50 & 50 & 50 & 47.0 & 47.0 & 2.0 & 4.0 \\
\hline M40-L60 & 40 & 60 & 37.6 & 56.4 & 2.0 & 4.0 \\
\hline M30-L70 & 30 & 70 & 28.2 & 65.8 & 2.0 & 4.0 \\
\hline M0-L100 & 0 & 100 & 0.0 & 94.0 & 2.0 & 4.0 \\
\hline
\end{tabular}


shape of powders and the pore structure of porous material were observed using the SEM (JSM-6610, JEOL, Japan), and the 3-point flexural strength was measured using the flexural strength tester (RB302, UNITECH, R\&B, Korea) at the span distance of $20 \mathrm{~mm}$ after processing the specimens to $3 \mathrm{~mm} \times 4 \mathrm{~mm} \times 30 \mathrm{~mm}$ for the strength of porous alumina ceramics. The electrical resistance was measured using the High-Resistance Meter (4339B, Agilent Technologies, USA) after processing the specimens to $20 \mathrm{~mm} \times 20$ $\mathrm{mm} \times 2 \mathrm{~mm}$ and applying $100 \mathrm{~V} \mathrm{(+)} \mathrm{bias} \mathrm{at} \mathrm{the} \mathrm{temperature}$ of $25^{\circ} \mathrm{C}$. In order to check whether a new phase was created due to the reaction between alumina and the added metallic oxides or not and the final phase, the measurement was carried out using the X-ray diffraction (D/MAX 2500 V/PC, Rigaku Corporation, Japan).

\section{Results and Discussion}

\subsection{Air permeability of porous material produced using the powders in the same size}

Figure 1 is the microscope images of commercial alumina small-sized powders(S), medium size (M) and large size (L) used in this experiment. Powders have an angled irregular polyhedron shape rather than a circular shape, and it is expected that the filling rate would be low due to powders in angled shape, so it will be helpful for improving the air permeability after sintering. Fig. 2 is the air permeability result of porous material prepared from mixtures with powders in the same size after sintering at $1600^{\circ} \mathrm{C}$ for $1 \mathrm{~h}$. The porous material produced only using the alumina powders in the largest size (L) among powders in three sizes showed a very high air permeability of $76.15 \mathrm{liter} / \mathrm{min} / \mathrm{cm}^{2}$ under the pressure of $100 \mathrm{kPa}$ where the pressure difference between gas flow was approximately 1 atmosphere. The porous material produced only using the alumina medium-sized powders showed $15.22 \mathrm{liter} / \mathrm{min} / \mathrm{cm}^{2}$ under the same pressure and the porous material produced only using the alumina powders in the small (S) size showed a very low air permeability of $0.44 \mathrm{liter} / \mathrm{min} / \mathrm{cm}^{2}$ under the same pressure.

The reason for such air permeability result can be explained by the difference of the relative density. When comparing the relative density of three kinds of specimens, the relative density of porous material using small-sized powder is $84.63 \%$, showing the lowest air permeability among three kinds of specimens and it is too dense to use it as a vacuum chuck. Also, the porous material from mediumsized powders showed the relative density of $64.37 \%$ and the porous material from large-sized powders showed $59.34 \%$ which was relatively low, indicating that the porous material had a higher air permeability as the relative density was lower. It is expected that such result is due to a difference in the relative density according to the size of starting powder. It is generally understood that the driving force is to reduce the whole surface energy in system of material, so the powders in a relatively small particle size has a wide specific surface area in case of sintering at the

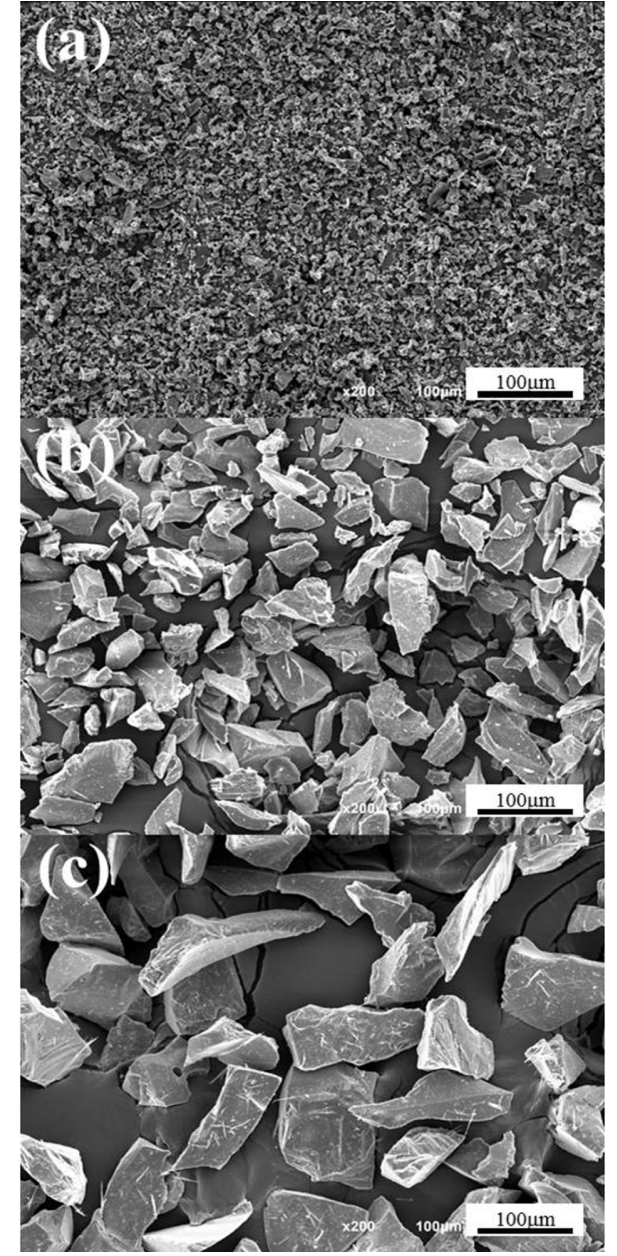

Fig. 1. SEM images of alumina powders: (a) small-sized powder (S), (b) medium-sized powder (M) and (c) largesized powder (L).

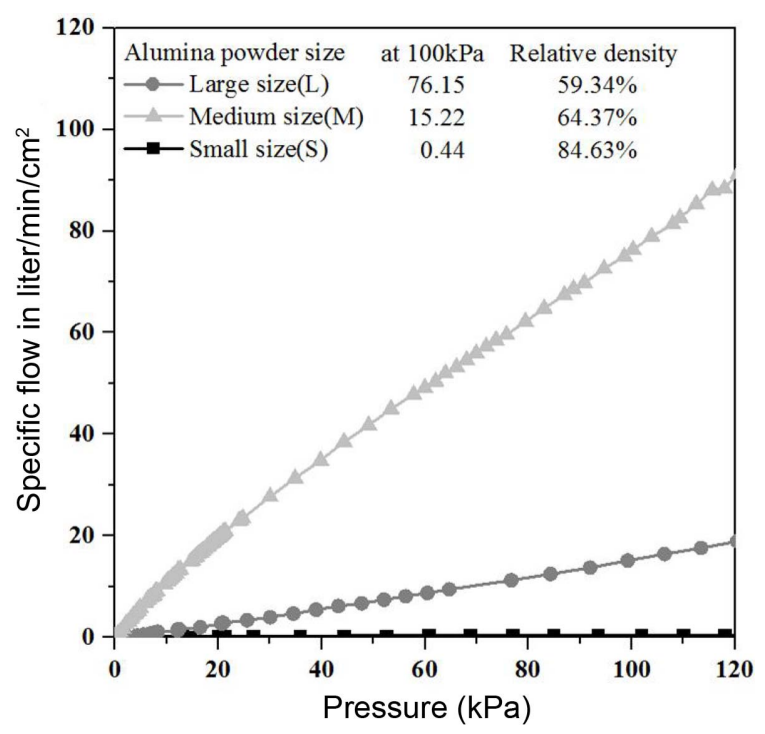

Fig. 2. Air permeability and relative density of porous alumina based ceramics prepared from mixtures with different size of starting powder after sintering at $1600^{\circ} \mathrm{C}$ for $1 \mathrm{~h}$. 
same sintering temperature, and it will have the highest driving force. Also, a vacuum chuck requires a high strength to withstand an impact that could occur when attaching an object for a long period of time. Therefore, the porous material from large-sized powders has a high air permeability, but due to its low relative density, it is expected that it will show a relatively low strength, so there will be a difficulty in using it as a vacuum chuck. The porous material from medium-sized powders also has a low permeability in comparison to the porous material from large-sized powder, so it is considered that it is difficult to use it as a vacuum chuck due to its low vacuum suction force. To solve such problem, it was intended to improve the strength by using increasing the relative density with the powder size mixing method and produce materials with high air permeability using relative large powders of two kinds which can make large open pores between large-sized powders.

\subsection{Pore characteristics of porous material accord- ing to mixing of alumina powder}

After making green bodies with the mixing ratio shown in Table 2 from medium-sized (M) and large-sized (L) powders, a change in the pore characteristics of porous material sintered at $1600^{\circ} \mathrm{C}$ for $1 \mathrm{~h}$ was observed. Fig. 3 shows the fracture microstructure of porous material using medium-sized powder (a), porous material using powder mixing method (b) (e) and porous material using large-sized powder (f). It can be confirmed that porous material using medium-sized powder (a) consists of relatively fine particles in comparison to porous material using large-sized powder (f) and porous material using large-sized powder (f) has large pores between large-sized powders. Also, porous material using mixing method $(b) \sim(e)$ shows the microstructures of mixture with medium-sized and large-sized powders.

Figure 4 shows the relative density of green bodies and sintered materials according to a change in the content of large-sized powders in medium-sized powder. The green density varies according to the mixing ratio when powders in two sizes are mixed. The green density increased as the content of large-sized powders increased up to $60 \%$ and it decreased when the content of large-sized powders exceeded $60 \%$. The density of porous material also changed in the same way with the green density. The sintered density increased as the content of large-sized powders increased up to $60 \%$ and it decreased when the content of large-sized powders exceeded $60 \%$. Also, a difference between the green density and the sintered density became larger as the content of medium-sized powders was larger because the medium-sized powders has a larger specific surface area than the large-sized powders so that it has a higher driving force for sintering than the large-sized powder. Among the green density results, green body of M40-L60 showed the highest density value as $66.38 \%$. Among the sintered density results, sintered body of M40-L60 also showed the highest density value as $67.83 \%$.

In order to confirm the effect of large open pores formed by

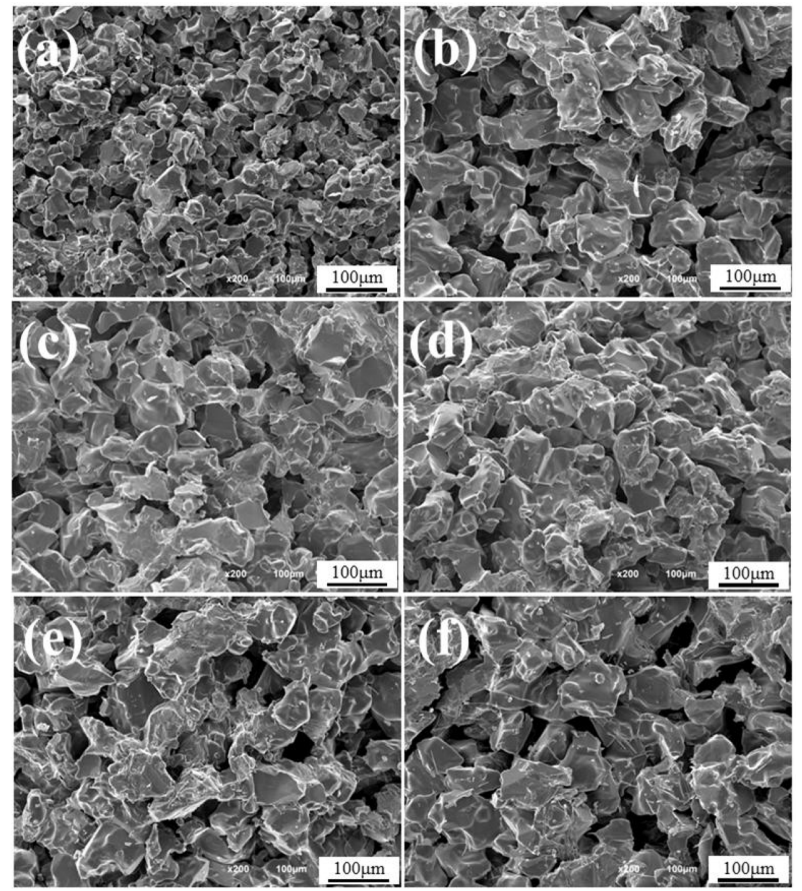

Fig. 3. Typical SEM image of the porous alumina-based ceramics sintered at $1600^{\circ} \mathrm{C}$ for $1 \mathrm{~h}$ : (a) M100-L0, (b) M70-L30, (c) M50-L50, (d) M40-L60, (e) M30-L70 and (f) M0-L100.

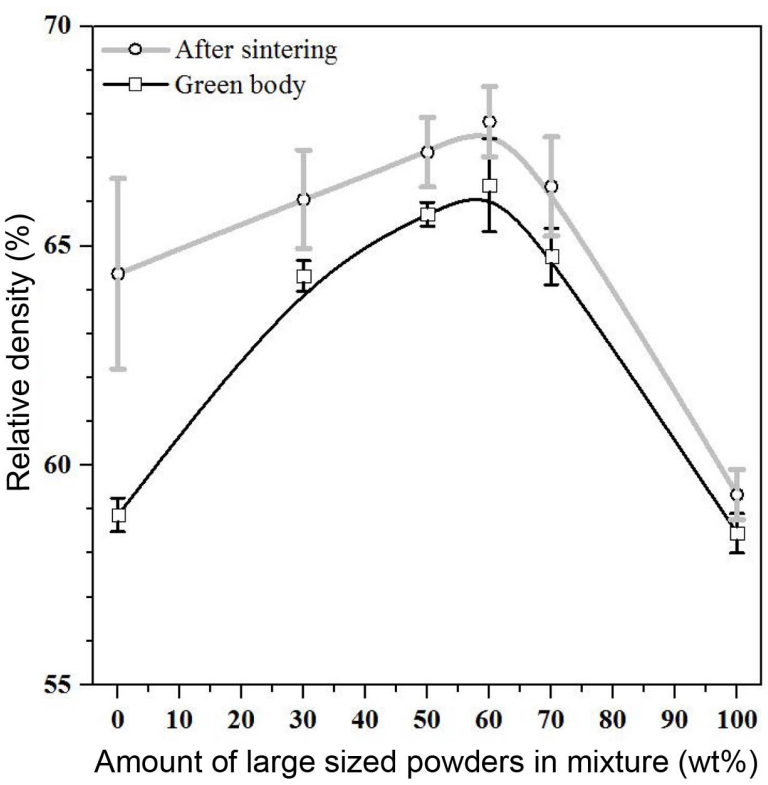

Fig. 4. Green and sintered density of porous alumina based ceramics prepared from powder mixtures with different contents of large sized powder (L) after sintering at $1600^{\circ} \mathrm{C}$ for $1 \mathrm{~h}$.

the large-sized powders as the content of large-sized powders in the medium-sized powders increased on a change in the average pore size, the pore structure was analyzed using the mercury porosimetry and the analysis result was shown in Fig. 5. The average pore size of porous material 


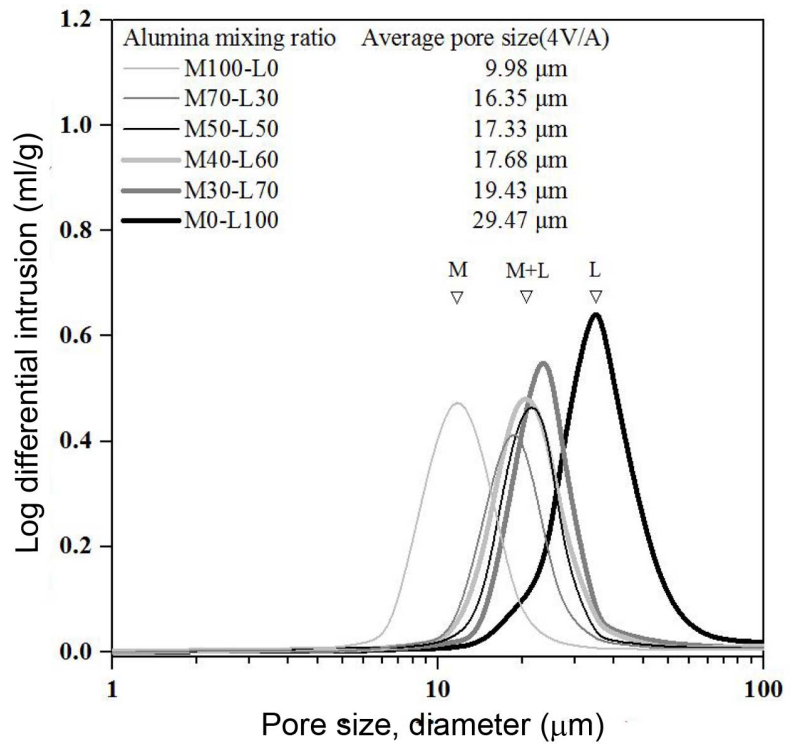

Fig. 5. Pore size distribution and average pore size of alumina based ceramics prepared from powder mixtures with different contents of large sized powder (L) after sintering at $1600^{\circ} \mathrm{C}$ for $1 \mathrm{~h}$.

prepared from only medium-sized powders is $9.98 \mu \mathrm{m}$, the average pore size of porous material prepared from the mixtures of powders in the medium and large sizes is approximately $16 \sim 19 \mu \mathrm{m}$, and the average pore size of porous material prepared from only with large-sized powders is $29.47 \mu \mathrm{m}$. It can be expected that the average pore size increases as the content of large-sized powders increases as shown in the result because large pores were generated between powders due to large-sized powders affect the average pore size of the sintered material.

Also, the air permeability was measured in order to check the effect of the content of large-sized powders since the air permeability of porous material was significantly influenced by the pore size. As shown in the average pore size result in Fig. 5, the average pore size increased as the content of the large-sized powders increased, and the air permeability also increased as the content of large-sized powders increased as shown in Fig. 6. Therefore, a change in the average pore size can be confirmed according to the change in the content of large-sized powders and it is expected that the air permeability depends on the average pore size. While the commercialized vacuum chuck as a reference shows a relatively low value of approximately $18 \mathrm{liter} / \mathrm{min} / \mathrm{cm}^{2}$ under the pressure of $100 \mathrm{kPa}$ where the pressure difference is approximately 1 atmosphere, the powder mixed material shows high air permeability between approximately 25 and $44 \mathrm{liter} / \mathrm{min} / \mathrm{cm}^{2}$ under the same pressure. This shows the level which could be used in parts including air bearing and semi-conductor vacuum chuck that require high air permeability. ${ }^{10)}$

Relatively large powders were used in this study, and a change in the pore structure and mechanical properties according to the mixing ratio between powders in two sizes

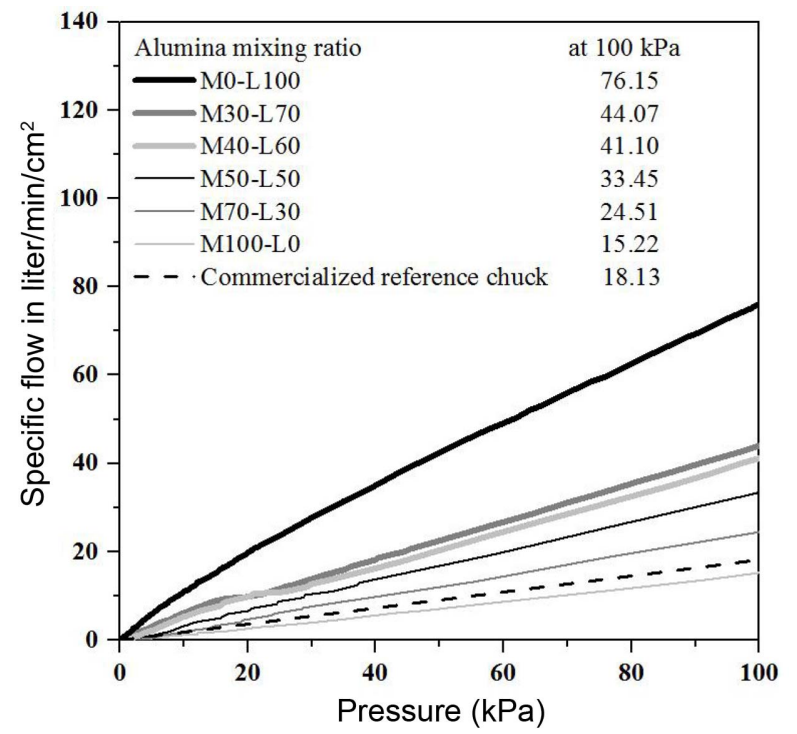

Fig. 6. Air permeability of porous alumina based ceramics prepared from powder mixtures with different contents of large sized powder (L) after sintering at $1600^{\circ} \mathrm{C}$ for $1 \mathrm{~h}$.

was examined. Since the pore structure and mechanical properties result from the microstructure, it was expected that the microstructure characteristics of green body and sintered body would vary according the size of starting powders used when powders in two sizes were mixed. In order to find appropriate microstructure for using as a vacuum chuck, microstructures were shown schematically in Fig. 7. Three kinds of microstructures using green body and sintered body in case of mixing powders were compared. Firstly, Fig. 7(a) is the schematic diagrams of anticipated microstructure of green body and sintered body in case of mixing small-sized powders and large-sized powders. Generally, when green body produced by mixing powders in two sizes is sintered, small-sized powders is sintered easily and the spaces of small-sized powders between large-sized powders would be remained as a pore. ${ }^{11)}$ Therefore, it is expected that it will show the highest green density among three kinds of types, so it will have the highest strength after sintering, but due to its high density, it will also have a low air permeability. On the contrary, in case of Fig. 7(c), only large-sized powders is used. Therefore, it is expected that it will show the lowest green density among three kinds of cases, and it is expected that it will show the lowest strength and a relatively high air permeability due to its low density after sintering. Fig. 7(b) shows the anticipated green and sintered body in case of mixing relatively large powders in two different sizes, showing the most similar shape with the result in this experiment. At first, according to the relative density result in this experiment, it has a high green density between $64 \%$ and $66 \%$, and the green body only from large-sized powders shows a low green density as approximately 59\%. Therefore, interstitial sites 


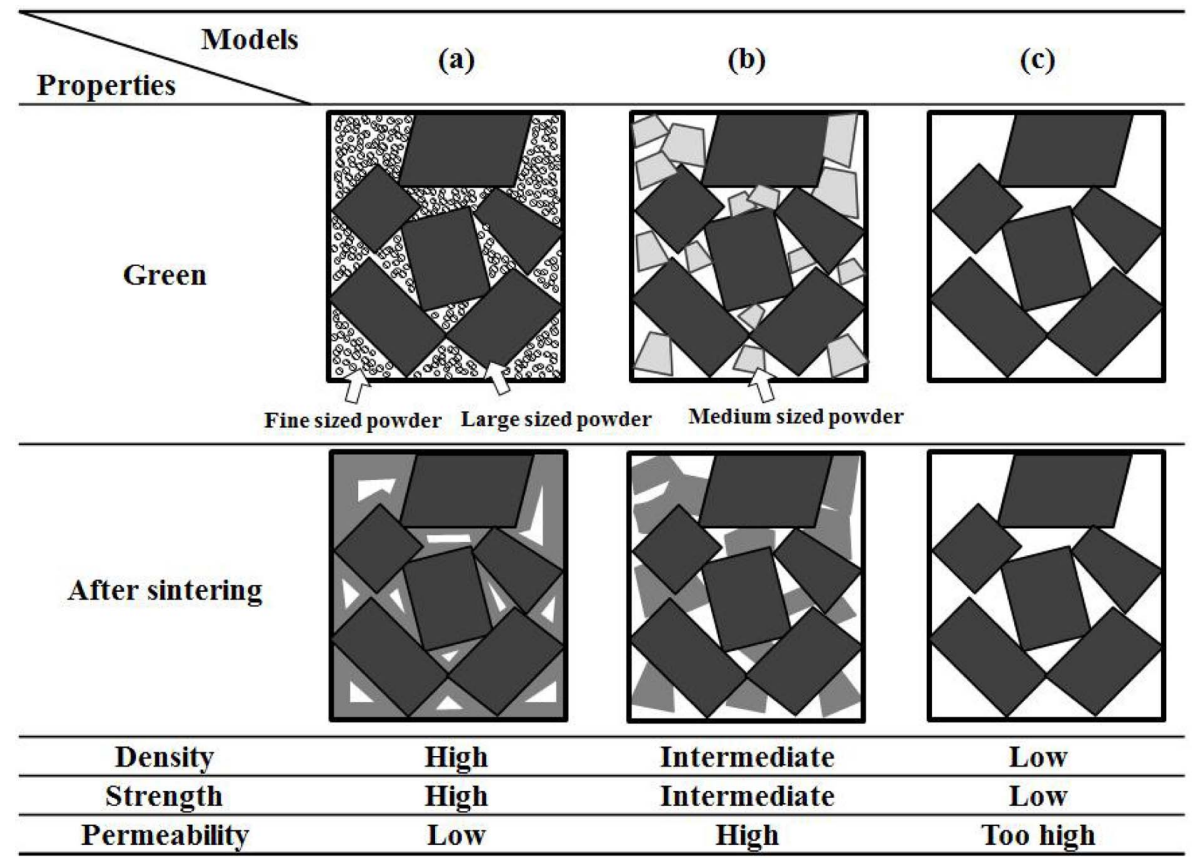

Fig. 7. Schematic diagrams of the anticipated microstructure: (a) fine and large sized powders in mixture, (b) medium and large sized powders in mixture and (c) large sized powders.

between large-sized powders are filled with medium-sized powders when two relatively large-sized powders in two different sizes are mixed and used, so it can be expected that it has a higher filling rate than the case of Fig. 7(c), where only large-sized powders are used. In other words, it is expected that the mechanical properties will be improved after sintering due to a high filling rate. In case of this experiment, powders in two different sizes are relatively large, so unique large pore size of powders is maintained as it is unlike the solid phase sintering behavior at the time of mixing small-sized powders and large-sized powder, so it is expected that it will have a high air permeability. Therefore, it has a high air permeability, and it is expected that it will have a high strength since it has a higher relative density than the porous material produced only with largesized powder. It is considered that Fig. 7(b) which shows the most similar shape in this experiment would be appropriate to be used as a vacuum chuck.

\subsection{Characterization of flexural strength accord- ing to powder mixtures}

In this study, the powder mixing method was used in order to improve low mechanical strength of porous alumina due to high porosity. Fig. 8 shows a change in the flexural strength according to the mixing rate, the content of largesized powders (L) in the medium-sized (M) powders. It is confirmed that as the content of large-sized powders increases, the flexural strength increases until the content of large-sized powders reaches $60 \%$, and when the content of large-sized powders exceeds $60 \%$, the flexural strength decreases. When comparing it with the relative density shown in Fig. 4, as the content of large-sized powders increases, it increases until the content of large-sized powders reaches $60 \%$, and when the content of large-sized powders exceeds $60 \%$, it decreases again, and the flexural strength increases as the relative density increases. The flexural strength increased because the filling rate increased as interstitial sites between large-sized powders

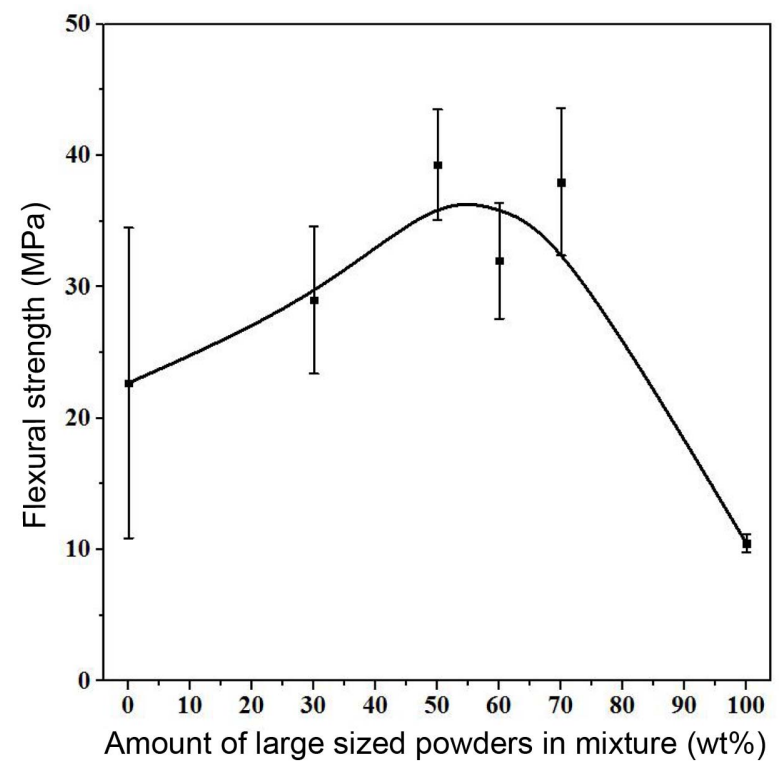

Fig. 8. Flexural strength of porous alumina based ceramics prepared from powder mixtures with different content of large sized powder (L) after sintering at $1600^{\circ} \mathrm{C}$ for $1 \mathrm{~h}$ 
were filled with medium-sized powders and it had a relatively high relative density accordingly after sintering, so the strength was improved. Also, the spaces between largesized powders are filled with medium-sized powders, increasing contact points between powders due to a relatively wide specific surface area of medium-sized powder, so the powders become relatively dense due to proper necking formation.

The studies on the density varying according to mixture of starting powders were mainly carried out by German ${ }^{12)}$ and McGeary. ${ }^{13)}$ And the mixing method of Furnas indicating that theoretically it has the highest green density at the volume fraction of the large-sized powders near $60 \sim 80 \mathrm{wt} \%$ is similar to the relative density result in this experiment. However, above-mentioned German and McGeary were able to increase the relative density through the mixing of different sized starting powders, but the purpose of this experiment is to keep the porosity through large pores created using relatively large alumina, not to produce dense material close to the theoretical density by inducing a high filling rate through mixing, so it is important to increase the air permeability of porous material through this method. Therefore, it was possible to improve the mechanical characteristics by adjusting the mixing ratio of powders and it was also possible to increase the air permeability of porous material by controlling the pore size using large pores of large-sized powders in this experiment.

\subsection{Characterization of electrical resistance accor- ding to alumina powder mixtures}

This study focuses on the study on the semi-conducting porous alumina material which has a lower electrical resistance than the conventional alumina. The generally known electrical resistance (volume resistance) of high-purity alumina has a value ranged between $1.7 \sim 7.2 \times 10^{14} \Omega \mathrm{cm}$. It is known that the electrical resistance of alumina is influenced by additives and the electrical resistance of alumina with high content of impurities is lower than that of highpurity alumina. ${ }^{14)}$ Therefore, it was intended to lower the electrical resistance of alumina in this experiment by including metallic oxides such as $\mathrm{MnO}_{2}$ and $\mathrm{TiO}_{2}$ to alumina. At first, phase transformation occurs in $\mathrm{MnO}_{2}$ into various phases including $\mathrm{Mn}_{2} \mathrm{O}_{3}, \mathrm{Mn}_{3} \mathrm{O}_{4}$ and $\mathrm{MnO}$ according to the temperature and oxygen partial pressure. Therefore, XRD was measured and the result was shown in Fig. 9 in order to confirm the final phase that could be formed by additives. According to the phase diagram of $\mathrm{Al}_{2} \mathrm{O}_{3}-\mathrm{TiO}_{2}$ $\mathrm{MnO}$ reported by Moreira and Segadaes, ${ }^{15)}$ the composition in this experiment is in the area of composition where $\mathrm{Al}_{2} \mathrm{O}_{3}$, $\mathrm{MnTiO}_{3}$ and $\mathrm{MnAl}_{2} \mathrm{O}_{4}$ coexist thermodynamically. However, in case of composition in this experiment, $\mathrm{Al}_{2} \mathrm{O}_{3}$ and $\mathrm{MnTiO}_{3}$ were confirmed mainly as the final phase according to the XRD result. It was caused by that the alumina powders used in this experiment were larger in comparison to $\mathrm{MnO}_{2}$ and $\mathrm{TiO}_{2}$ powders added as additives, so there were less contact points where chemical reaction could occur due to

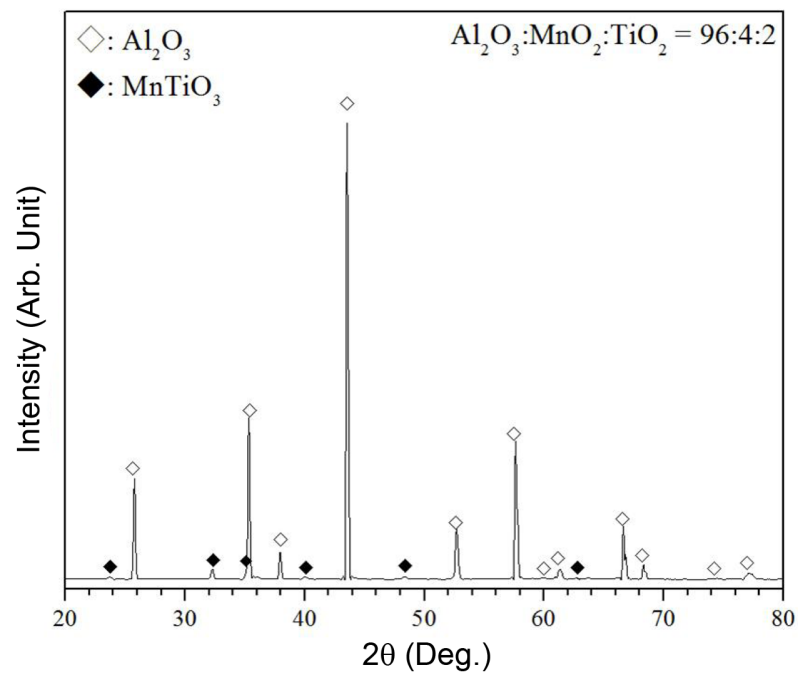

Fig. 9. X-ray diffraction pattern of sample (M100-L0) sintered at $1600^{\circ} \mathrm{C}$ for $1 \mathrm{~h}$.

relatively less specific surface area, so less alumina compound formed. Therefore, when large alumina powders was used, a very low peak intensity of $\mathrm{MnAl}_{2} \mathrm{O}_{4}$ which could be generated through the reaction with $\mathrm{MnO}_{2}$ was shown, and it is expected that a relative high peak from $\mathrm{MnTiO}_{3}$ which was the compound of $\mathrm{MnO}_{2}$ and $\mathrm{TiO}_{2}$ could be confirmed from the XRD result. Also, the result showing that the peak of corundum which was the high temperature phase of alumina was shifted was shown and it is inferred that metallic oxides make solid solution partially, and it has been reported that $\mathrm{TiO}_{2}$ is soluble to alumina by $0.27 \%$ at a temperature ranged between $1300 \sim 1700^{\circ} \mathrm{C} .^{16)}$ It has been also reported that such metallic oxides could reduce the electrical resistance of alumina, and as a typical example, when metallic oxides such as $\mathrm{TiO}_{2}$ are added, $\mathrm{Al}^{+3}$ is replaced by $\mathrm{Ti}^{+4}$ according to the non-stoichiometric equation mechanism, creating excess electron and reducing electrical resistance. ${ }^{17-19)}$ Therefore, the electrical resistance of alumina deceases as the content of $\mathrm{TiO}_{2}$ increases.

$$
2 \mathrm{TiO}_{2} \stackrel{\mathrm{Al}_{2} \mathrm{O}_{3}}{\Longleftrightarrow} 2 \mathrm{Ti}_{\dot{A} l}+3 \mathrm{O}_{o}+\frac{1}{2} \mathrm{O}_{2}(g)+2 e
$$

Also, $4 \mathrm{wt} \%$ of $\mathrm{MnO}_{2}$ was added to all specimens equally, and $\mathrm{MnO}_{2}$ is an additive for alumina material used in LCD photo process and it is known that it can reduce the reflectivity effectively in the photo process due to back color of $\mathrm{MnO}_{2}{ }^{20)}$ and when it is sintered with alumina together, $\mathrm{MnAl}_{2} \mathrm{O}_{4}$ is formed. ${ }^{21)} \mathrm{It}$ is reported that $\mathrm{MnAl}_{2} \mathrm{O}_{4}$ formed in this way has a significantly lower electrical resistance as approximately $1.0 \times 10^{3} \Omega \mathrm{cm}$ in comparison to alumina and, ${ }^{22)} \mathrm{MnTiO}_{3}$ has a electrical resistance of approximately $1.8 \times 10^{7} \Omega \mathrm{cm}^{23)}$ It is considered in this study that low electrical resistance of alumina was mainly influenced by $\mathrm{MnTiO}_{3}$ 


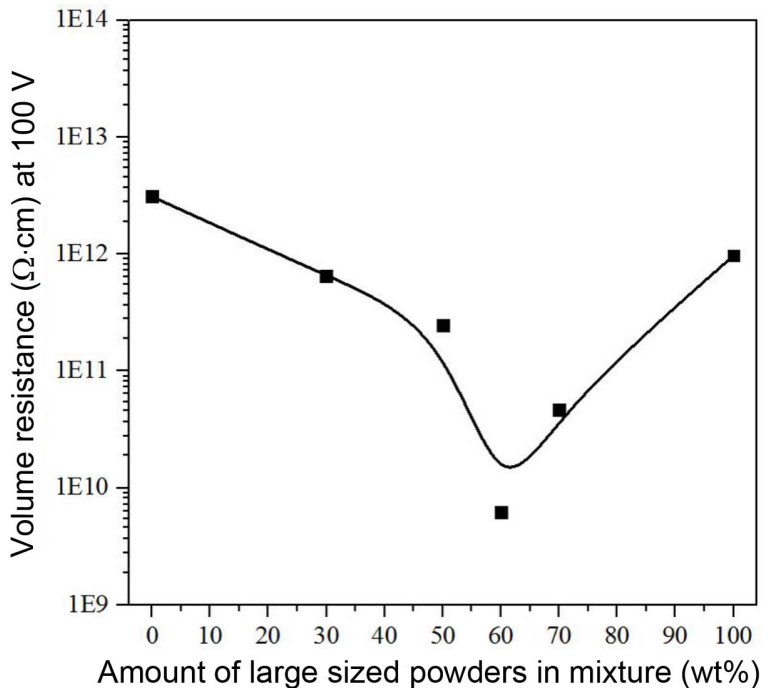

Fig. 10. Electric resistance of porous alumina based ceramics prepared from powder mixtures with different contents of large sized powder (L) after sintering at $1600^{\circ} \mathrm{C}$ for $1 \mathrm{~h}$

Figure 10 is the graph for confirming a change in the electrical resistance of porous alumina according to the mixing powders in two different sizes, and it was confirmed whether the electrical resistance changed or not as the content of large-sized powders in the medium-sized powders increased. The electrical resistance result of all specimens shows a significant lower value in the range between $2.4 \times$ $10^{11}$ and $6.2 \times 10^{9} \Omega \mathrm{cm}$ in comparison to approximately $1 \times$ $10^{15} \Omega \mathrm{cm}$ which is the generally known electrical resistance of alumina. It is inferred that the electrical resistance of alumina decreased due to the addition of metallic oxides, so it is expected that the problem of electrostatic polarization which could occur in the FPD process due to a high electrical resistance of alumina mentioned above could be solved. Also, when comparing the relative density of porous alumina shown in Fig. 4 with the electrical resistance in Fig. 10, the electrical resistance was directly opposite to the relative density result. It is confirmed that as the content of large-sized powders increases, the electrical resistance decreases rapidly until the content of large-sized powders reaches $60 \%$, and the relative density decreases and the electrical resistance increases until the content of large-sized powders reaches $100 \%$ after exceeding $60 \%$. It is inferred from such result that a relationship between the electrical resistance and the relative density exists. The interstitial sites between large-sized powders are filled with the mediumsized powders as the relative density becomes higher, so the filling rate increases and the distance between powders becomes closer, ensuring proper necking formation, so it becomes more easier for excess electron created from the substitution of metallic oxides to move in alumina porous material. Also, it is confirmed that it has a lower electrical resistance than the pure alumina due to the second phase which has a low electric resistance including $\mathrm{MnAl}_{2} \mathrm{O}_{4}$ formed by alumina and $\mathrm{MnO}_{2}$ and $\mathrm{MnTiO}_{3}$ formed by $\mathrm{MnO}_{2}$ and $\mathrm{TiO}_{2}$.

\section{Conclusions}

It was possible to improve the mechanical strength of porous alumina by increasing the relative density using the method to mix powders in two different sizes and increasing the air permeability through the generation of large open pores using relatively large powders. A possibility to produce porous alumina having a low electrical resistance by adding metallic oxides to alumina was confirmed. In case of porous alumina prepared from the above process, the flexural strength increased and the electrical resistance decreased as the relative density increased. Among them, M50-L50 material showed an excellent flexural strength of 43.5 $\mathrm{MPa}$ and M40-L60 material showed a relatively high density of $68.30 \%$ and the lowest electrical resistance of 6.2 $\times 10^{9} \Omega \mathrm{cm}$. It was also confirmed that the average pore size of porous material increased as the content of large-sized powders in medium-sized powders increased, and it had an excellent air permeability of approximately $25 \sim 45$ liter/ $\mathrm{min} / \mathrm{cm}^{2}$ under the pressure of $100 \mathrm{kPa}$ where the pressure difference was approximately 1 atmosphere.

\section{Acknowledgments}

This material is based upon work supported by Ministry of Trade, Industry \& Energy (MOTIE, Korea) under Industrial Technology Innovation Program. No.10052935

\section{REFERENCES}

1. S. H. Chae, J. H. Eom, Y. W. Kim, I. H. Song, H. D. Kim, J. S. Bae, S. M. Na, and S. I. Kim, "Porosity Control of Porous Zirconia Ceramics," J. Korean Ceram. Soc., 45 [1] 65-8 (2008).

2. Y. Seki, S. Kose, T. Kodama, M. Kadota, T. Ogura, K. Tanimoto, and I. Matsubara, "Production Method of Porous Silica Compacts Containing Submicron Pores," J. Ceram. Soc. Jpn., 96 [9] 920-24 (1988).

3. J. F. Zievers, P. Eggerstedt, and E. C. Zievers, "Porous Ceramics for Gas Filtration," Am. Ceram. Soc. Bull., 70 [1] 108-11 (1991).

4. K. Y. Lim, Y. W. Kim, I. H. Song, H. D. Kim, and J. S. Bae, "Effect of Frit Content on Microstructure and Flexural Strength of Porous Frit-bonded $\mathrm{Al}_{2} \mathrm{O}_{3}$ Ceramics," J. Korean Ceram. Soc., 47 [6] 529-33 (2010).

5. I. H. Song, I. M. Kwon, H. D. Kim, and Y. W. Kim, "Processing of Microcellular Silicon Carbide Ceramics with a Duplex Pore Structure," J. Eur. Ceram. Soc., 30 2671-76 (2010).

6. Y. Okiyama and R. Yamaguchi, "Enhanced Ceramic Material for Precision Alignment Mechanism"; US Patent 10/ 895,091 (July 21, 2004).

7. C. Furnas, "Grading Aggregates-I. Mathematical Relations for Beds of Broken Solids of Maximum Density," Ind. Eng. 
Chem., 23 [9] 1052-58 (1931).

8. S. Kwon and G. L. Messing, "Constrained Densification in Boehmite-Alumina Mixtures for the Fabrication of Porous Alumina Ceramics," J. Mater. Sci., 33 913-21 (1998).

9. A. Kritikaki and A. Tsetsekou, "Fabrication of Porous Alumina Ceramics from Powder Mixtures with Sol-gel Derived Nanometer Alumina: Effect of Mixing Method," $J$. Eur. Ceram. Soc., 29 1603-11 (2009).

10. I. H. Song, M. J. Park, H. D. Kim, Y. W. Kim, and J. S. Bae, "Microstructure and Permeability Property of Si Bonded Porous SiC with Variations in the Carbon Content," J. Korean Ceram. Soc., 47 [6] 546-52 (2010).

11. J. Li, Y. Pan, F. Qiu, L. Huang, and J. Guo, "Alumina Ceramics Fabricated from Bimodal Alumina with Additives," J. Mater. Sci. Eng. A, 435 611-19 (2006).

12. R. M. German, "Prediction of Sintered Density for Bimodal Powder Mixtures," Metall. Trans. A, 23 [5] 1455-65 (1992).

13. R. K. McGeary, "Mechanical Packing of Spherical Particles," J. Am. Ceram. Soc., 44 [10] 513-22 (1962).

14. K. S. Cho, H. K. Lee, Y. I. Park, and M. Y. Kim "Electrical Properties of Large Alumina Ceramics Prepared by Various Processing," J. Korean Ceram. Soc., 49 [2] 179-84 (2012).

15. M. C. Moreira and A. M. Segadaes, "Phase Equilibrium Relationships in the System $\mathrm{Al}_{2} \mathrm{O}_{3}-\mathrm{TiO}_{2}-\mathrm{MnO}$, Relevant to the Low-Temperature Sintering of Alumina," J. Eur. Ceram. Soc., 16 1089-98 (1996).

16. A. Guidara, K. Chaari, and J. Bouaziz, "Effect of Titania Additive on Structural and Mechanical Properties of Alu-
mina-Fluorapatite Composites," J. Mater. Sci. Technol., 28 [12] 1130-36 (2012).

17. H. J. Kim, Y. G. Shin, H. K. Ahn, and D. W. Kim, "A Study on the Holding of LED Sapphire Substrate Using Alumina Electrostatic Chuck with Fine Electrode Pattern," J. Kor. Inst. Surf. Eng., 44 [4] 165-71 (2011).

18. K. J. Jeong, Y. G. Park, Y. S. Lee, T. Y. Cho, and H. G. Chun, "A Study on the Fabrication and Characterization of Alumina Electrostatic Chuck for Silicon Wafer Processing," J. Sensor Sci. \& Tech., 8 [6] 481-86 (1999).

19. T. Watanabe, T. Kitabayashi, and C. Nakayama, "Electrostatic Force and Absorption Current of Alumina Electrostatic Chuck," Jpn. J. Appl. Phys., 31 [7] 2145-50 (1992).

20. I. H. Bang, K. O. Kim, and S. J. Lee, "Fabrication and Characteristics of Black Alumina for LCD Photo Processing Material," J. Ceram. Process. Res., 15 [6] 525-29 (2014).

21. O. A. Bulavchenko, S. V. Tsybulya, P. G. Tsyrul'nikov, T. N. Afonasenko, S. V. Cherepanova, and E. Yu. Gerasimov, "Chemical and Structural Transformations in Mananese Aluminum Spinel of the Composition $\mathrm{Mn}_{1.5} \mathrm{~A}_{1.5} \mathrm{O}_{4}$ During Heating and Cooling in Air," J. Struct. Chem., 51 [3] 500-6 (2010).

22. A. Petric and H. Ling, "Electrical Conductivity and Thermal Expansion of Spinels at Elevated Temperatures," $J$. Am. Ceram. Soc., 90 [5] 1515-20 (2007).

23. R. S. Singh, T. H. Ansari, and R. A. Singh, "Electrical Conduction in $\mathrm{MnTiO}_{3}$ Single Crystal," Proc. Indian Natl. Sci. Acad., 61 [6A] 425-32 (1995). 